\title{
Study on the measurement method of environmental pollution loss based on shadow price model of waste gases emission from energy consumption in China's industrial parks
}

\section{Xiuyan Han}

Nanjing university of Aeronautics and Atronautics

Tao Sun ( $\square$ nuaastao@163.com )

Nanjing University of Aeronautics and Astronautics College of Economics and Management https://orcid.org/0000-0003-3121-2340

\section{Taiyi Cao}

Dalian University of Technology

\section{Research}

Keywords: Loss of waste gas emission, environmental pollution, measure model, shadow price, industrial parks

Posted Date: December 10th, 2019

DOI: https://doi.org/10.21203/rs.2.18459/v1

License: (c) (1) This work is licensed under a Creative Commons Attribution 4.0 International License.

Read Full License 


\title{
Study on the measurement method of environmental pollution loss based on shadow price model of waste gases emission from energy consumption in China's industrial parks Xiuyan Han ${ }^{1}$, Tao Sun ${ }^{1 *}$, Taiyi Cao ${ }^{2}$
}

1 College of economics and management, Nanjing university of aeronautics and astronautics, Nanjing Jiangsu 211106 China

2 School of economics and management of Dalian university of technology, Dalian, Liaoning 116024 China

Correspondence: nuaastao@163.com

\begin{abstract}
Background: China's industrial parks are areas where energy consumption is relatively concentrated and air pollution is relatively serious. Air pollution threatens the living environment, health and even life of the residents around the industrial park. Therefore, the measurement of air pollution loss and its application have been raised, and gradually become an important problem to be solved.

Results: In order to explore the measurement method of environmental pollution loss from energy consumption waste gas emission in industrial parks, this paper, based on literature review, draws lessons from the latest research results at home and abroad, fully considers the actual situation of energy consumption waste gas emission and environmental pollution control in China's industrial parks, and constructs the shadow price measurement model of environmental pollution loss from energy consumption waste gas emission. Taking Nanjing MV industrial park as an example, the application test of environmental pollution loss of energy consumption waste gas emission is carried out by using the relevant statistical data of the park, and the validity of the model is verified.

Conclusions: The results show that the shadow price model is more effective for the Measurement of environmental pollution loss of exhaust gas emissions from energy consumption in industrial parks. The research results are of great significance to guide exhaust emission enterprises to strengthen environmental pollution loss control and support local governments to formulate energy consumption and exhaust emission standards and relevant policies for industrial parks
\end{abstract}

Key words: Loss of waste gas emission, environmental pollution, measure model, shadow price, industrial parks 


\section{Background}

The construction of China's industrial parks began with the pilot project of Dalian Economic and Technological Development Zone in 1984, and its development has gone through three stages. The first stage is the pilot stage from 1994 to 1998 , featuring the construction of economic and technological development zones. The second stage is the improvement stage from 1988 to 2008, which is characterized by the construction of high-tech development zones. The third stage is the construction stage of eco-industrial parks from 2008 to now, featuring the construction of emerging eco-industrial parks. Although the construction of industrial parks in China has pointed out the direction and focus of future development, due to various reasons, the environmental pollution of industrial parks is still at a very high level and quite serious situation, especially the relatively serious pollution of the atmospheric environment. Because the production of industrial parks in China mainly uses petrochemical energy, a large amount of petrochemical energy is consumed, resulting in a huge amount of waste gas emissions [1]. According to the statistics of the International Environmental Organization, China's per capita $\mathrm{CO}_{2}$ emission has exceeded 7 tons since 2013, making it the country with the largest per capita $\mathrm{CO}_{2}$ emission in the world. In China's $\mathrm{CO}_{2}$ emissions, industrial energy consumption is the main $\mathrm{CO}_{2}$ emissions, according to the author's research results [2], the intensity of $\mathrm{CO}$ emission from industrial production energy consumption in China is still showing an upward trend, and the growth rate is also rising in the near future. The specific research results are detailed in Figure 1.

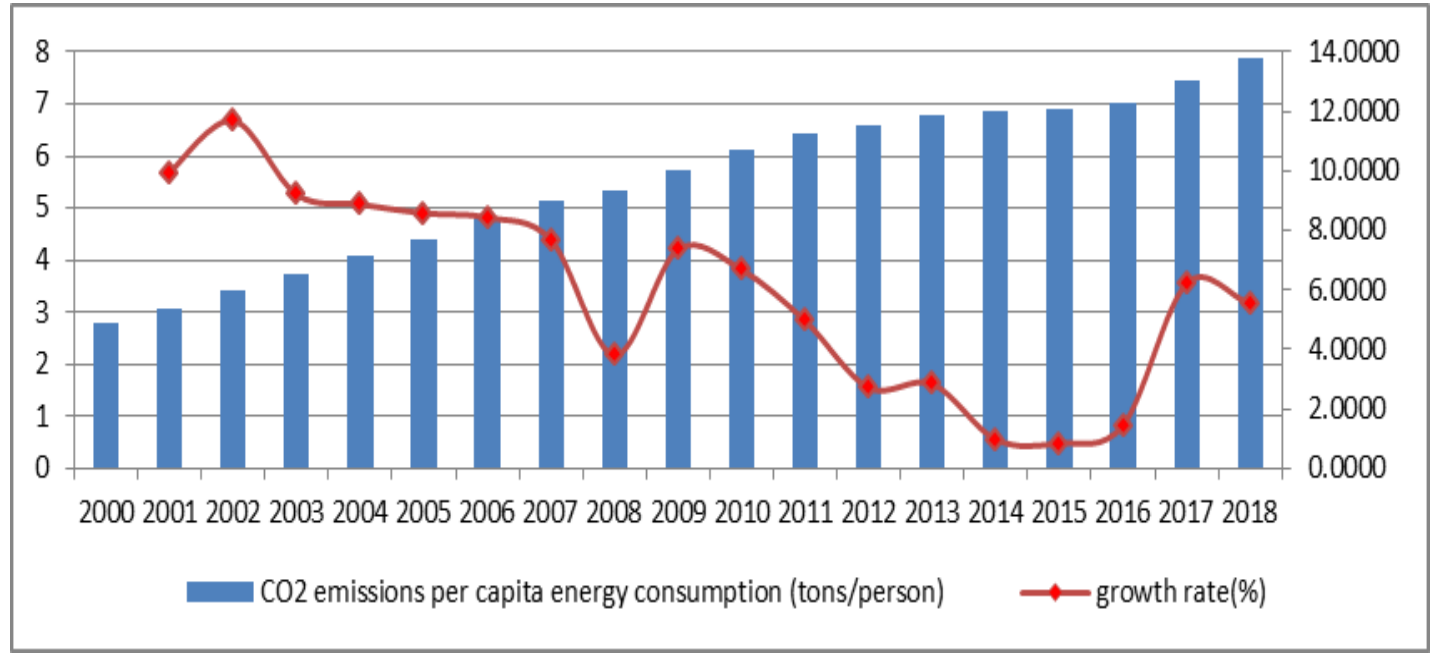

FIG.1.Industrial Energy Consumption $\mathrm{CO}_{2}$ Emission Intensity and Its Growth Trend Chart in China

In China's economic development, industrial parks are the main form of economic development and play an 
important role in promoting rapid economic growth. According to the development status of Nanjing MV Industrial Park, the industrial park has a greater contribution rate in economic development. The per capita output value of the producers of Nanjing MV Industrial Park reaches 635109 yuan, and the corresponding per capita emission intensity reaches 15.37 tons per person, which is nearly twice the national average level. The intensity of $\mathrm{SO}_{2}$ emission, $\mathrm{NO}_{2}$ emission, $\mathrm{CO}$ and $\mathrm{CO}_{2}$ emission, $\mathrm{O}_{3}$ emission, $\mathrm{PM}_{2.5}$ and $\mathrm{PM}_{10}$ emission from industrial parks are more than twice the national average. Therefore, China's industrial parks have become a major disaster area of environmental pollution. Environmental pollution caused by energy consumption waste gas emission in industrial parks has affected the living environment, health and even life of residents. Under such circumstances, the measurement of environmental pollution loss from energy consumption waste gas emission of industrial parks in China and its application have been put forward, and gradually become an important issue to be solved urgently.

The research on shadow price measurement of pollutants emitted from energy consumption waste gas emission at home and abroad originated in the 1960s. Western countries used human capital as the earliest method to measure environmental pollution loss, and regarded the human resources consumed in the process of environmental pollution control as the value of environmental pollution loss [3]. According to the results of literature review at home and abroad, the research of this topic mainly focuses on two aspects: the environmental pollution loss measurement of waste gas emission and the shadow price measurement model of pollutants. There are relatively few studies on the measurement methods of environmental pollution loss caused by waste gas emission and the application of the methods both at home and abroad. Overseas developed countries research is relatively in-depth. Nepalese scholars used empirical research methods to study the impact of air pollution on land and surface water, and predicted the degree of pollution [4]. American scholars had analyzed the relationship between air pollution and human health by means of a combination of various methods, and had made a thorough study of the guesswork method for the loss of air pollution [5]. Singaporean scholars used damage function and large data method to study environmental pollution loss caused by atmospheric particulate pollutants [6]. American scholars had studied the measurement method of carbon emission loss and its application by using the element composition and emission mechanism of carbon 
emission process [7]. Mexican scholars analyzed the silly pollution events in Mexico City in the 18th century, and studied the assessment methods and applications of the economic losses caused by the silly pollution [8]. Chinese scholars had analyzed the environmental responsibility of industrial production sewage discharge, studied the measurement method of environmental responsibility and its application [9], and analyzed the environmental pollution caused by the "three wastes" discharged from large open pit mines, and studied the specific assessment methods of environmental pollution losses [10]. Dutch scholars assessed the economic losses caused by human health and vegetation damage by using the global air pollution regional life cycle impact assessment method [11]. Chinese scholars had analyzed the relationship between air pollution, disease burden and health economic losses, especially the calculation method of economic losses caused by air pollution [12]. Argentine scholars had studied the method and application of in situ determination of atmospheric pollution losses by lichen susceptibility [13]. French scholars have studied the method of assessing air pollution losses in industrial zones by using tree chemistry method, and explored the innovation of the method of assessing environmental pollution losses [14].

The research on shadow price measurement model at home and abroad began in the 1960s. There are usually two basic methods [15]. The first method is the parametric method, which is a method to determine the shadow price by using the parameter variables modeling. Early studies on parametric methods to determine shadow prices mostly used production functions to estimate shadow prices [16-18]. Later, the parametric model method of shadow price has been extended to use cost function to model [19-20]. From 1980 to now, the parametric method of shadow price has developed to use shadow price [21-23]. Gradually, using directional distance method to solve shadow price has become the mainstream of parametric methods. Shadow price is constructed by directional distance function, which can be divided into shadow price method based on Shephard input directional distance function [24-25]. Shadow price method based on Shephard output directional distance function [26-28]. The second method is a non-parametric method based on Data Envelopment Analysis (DEA). Data Envelopment Analysis is a new field of interdisciplinary research of operations research, management science and mathematical economics. This method is a quantitative analysis method for evaluating the relative effectiveness of comparable units of the same type by using linear 
programming method based on multiple input and output indices [29]. In the application of this method, researchers still use directional distance function as a tool to construct shadow price model.

From the above literature review, it can be seen that environmental pollution losses from energy consumption waste gas emission have been studied at home and abroad. Overseas research is relatively perfect, and a systematic system of theories and methods has been basically formed. However, in the existing research, there are relatively few research results on the methods and applications of environmental pollution loss measurement of energy consumption waste gas emission in industrial parks. There are even fewer literatures on the measurement method of environmental pollution loss using shadow price to measure energy consumption waste gas emission in industrial parks and its application. Industrial parks are a relatively common economic development situation in the world, with relatively concentrated energy consumption and relatively serious air pollution. Therefore, in this case, it is particularly important and urgent to study the method of using shadow price to measure the environmental pollution loss of energy consumption waste gas emission in industrial parks.

\section{Methods}

\subsection{Environmental Technology Analysis}

Shadow price model is based on directional distance function and planning method. Shadow price of atmospheric pollutants is a method to measure the price level of atmospheric pollutants in a production decision-making system, considering energy input and unexpected output. In order to measure the shadow price of atmospheric pollutants effectively, Fare R et al. [30] proposed the concept of environmental technology. The meaning of environmental technology is that in the production decision-making system, because of the existence of energy consumption, the production system will also produce unexpected environmental pollution losses at the same time as the expected output value. This technology reflects the technical structural relationship between input and output in the production system, characterized by Weak Disposability and Null-jointness. Assuming that a certain industrial park has $\mathrm{N}$ production decision-making units (DMU), each (DMU) has K inputs; energy is one of the important forms of input. The input vector of industrial park production can be expressed as: 
$r=\left(r_{1}, r_{2}, \cdots, r_{k}\right) \in R_{k}^{+}$, the expected output vector of industrial park production can be expressed as: $y=\left(y_{1}, y_{2}, \cdots, y_{n}\right) \in R_{n}^{+}$, unexpected output vectors are mainly the vectors formed by atmospheric pollutant emissions. The vectors of atmospheric pollutants can be expressed as follows: $u=\left(u_{1}, u_{2}, \cdots, u_{m}\right) \in R_{m}^{+}$. If the input-output combination function of industrial park is expressed in $\mathrm{P}(\mathrm{x})$, the expression of the combination function is as follows:

$$
P(x)=\{(y, u): \operatorname{input}(r), \text { output }(y, u)\}, r \in R_{k}^{+}
$$

The idea of environmental technology is embodied in the above formula. Energy consumption in input variables makes the production system produce both expected output value and undesirable pollutants. Under the constraints of environmental technology, the combination function $\mathrm{P}(\mathrm{x})$ has the following properties:

(1) Input is disposable. According to the definition of free disposability, for the input variables in the above formula, if there is $x^{\prime} \geq x$, then there must be $P(x) \subseteq P\left(x^{\prime}\right)$.

(2) The expected output is disposable. According to the definition of free disposability, if there are $(y, u) \in P(x)$ and $y^{\prime} \leq y$, then there must be $\left(y^{\prime}, u\right) \in P(x)$ for the input variables in the above formula.

(3) Unexpected output has weak disposability. According to the definition of weak disposability, if $(y, u) \in P(x)$ and $0 \leq \beta \leq 1$, then there must be: $\left(\beta_{y}, \beta_{u}\right) \in P(x)$. Weak disposability of unexpected output means that expenditure expected output can be reduced through environmental pollution control. It also shows that the reduction of unexpected output is very difficult and requires a high cost of governance.

(4) There is zero correlation between expected output and unexpected output. That is to say, the correlation between expected output and unexpected output at zero point is the strongest, which means reducing the unexpected output at the cost of simultaneously reducing the expected output. The mathematical expression of this property is: if there is $(y, u) \in P(x)$ and $\left(y^{\prime}, u^{\prime}\right) \leq(y, u)$, then there must be $\left(y^{\prime}, u^{\prime}\right) \in P(x)$.

Environmental technology is the basis of calculating shadow price. In order to effectively measure the shadow price of energy consumption emission pollutants in industrial parks, the principle of environmental technology is analyzed below. The detailed schematic diagram is shown in Figure 2. 


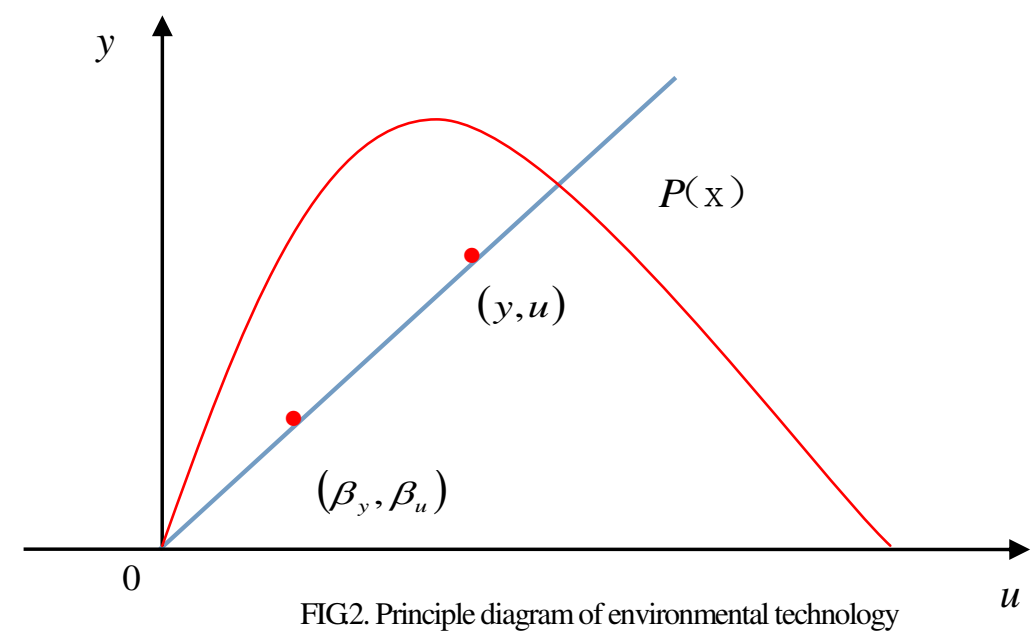

In the decision-making system of energy consumption waste gas emission in industrial parks, the combination function of expected output and expenditure expected output is $\mathrm{P}(\mathrm{x})$. Any point in rectangular coordinates is a combination of expected output and unexpected output. The purpose of shadow price calculation is to find the combination that maximizes the expected output rather than the minimum expected output. If variable $(y, u)$ is an observation point of the combined function $\mathrm{P}(\mathrm{x})$, and $\left(\beta_{y}, \beta_{u}\right)$ is the equidistant reduction point of $(y, u)$, it shows that the point after reduction according to a certain proportion is still in the $\mathrm{P}(\mathrm{x})$ range. Because expected output and unexpected output have the characteristic of Null-jointness, zero is the only common point between them. According to the relevant theories and the latest research results, the optimal combination of expected output and unexpected output in the $\mathrm{P}(\mathrm{x})$ interval is the distance from the combination point to the $\mathrm{P}(\mathrm{x})$ combination function.

\subsection{Construction of Directional Distance Function of Output}

As early as the early 1950s, Shephard (1953) put forward the concepts of input distance function and output distance function, and studied the specific solution of directional distance function. It was not until the mid-1990s that Chambers et al. (1995) began to standardize directional distance function in theory. Chung and Fare (1996) defined the definition of directional distance function and studied the construction of directional distance function. Directional distance function is widely used in solving optimization problems. Within the range of $\mathrm{P}(\mathrm{x})$ of the combination function, let's take a point $(y, u)$, which is the combination of expected output $y$ and unexpected output $u$. To find the distance from this point to the combination function $\mathrm{P}(\mathrm{x})$ is, in fact, to find the value of $(\mathrm{y}, \mathrm{u})$ when the combination 
output function $\mathrm{P}(\mathrm{x})$ reaches the maximum value when the directional vector expands or contracts to the greatest extent in the same proportion. The schematic diagram of directional distance function is shown in Figure 3.

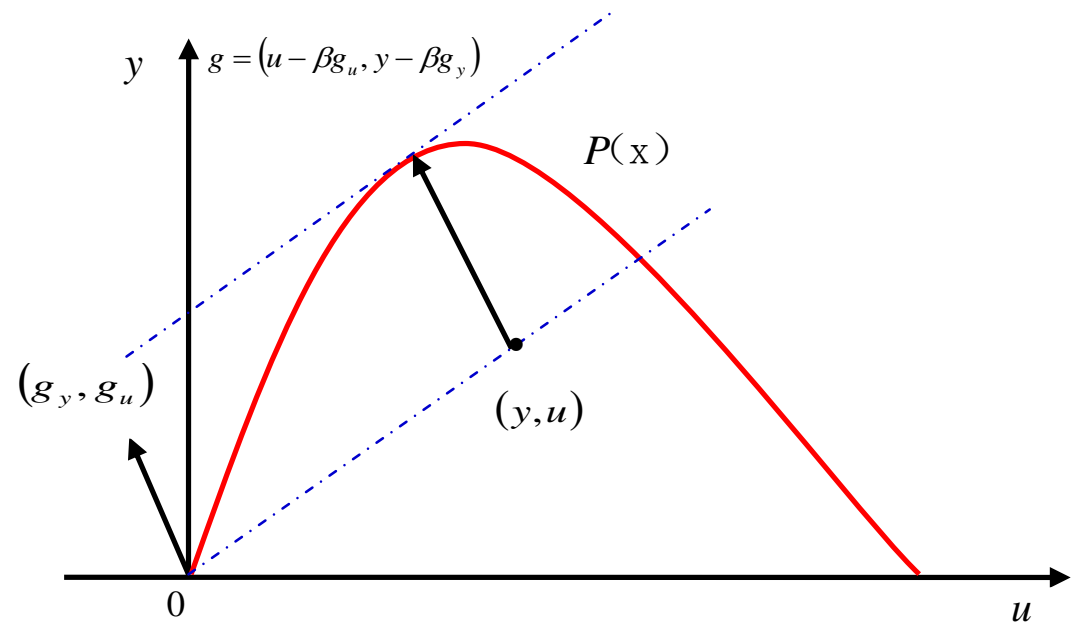

FIG3. Schematic diagram of directional distance function distance function

As can be seen from the above figure, the actual output point of the production department in the industrial park is the combination of expected output and unexpected output, which always lies in the production interior and there is $(\mathrm{y}, \mathrm{u}) \in \mathrm{P}(\mathrm{x})$. Suppose that the direction vector of the combined output function is $g=\left(\mathrm{g}_{y}, \mathrm{~g}_{u}\right)$ and $g \neq 0$, and the direction vector at $(\mathrm{y}, \mathrm{u})$ point is $g=\left(\mathrm{y}-\beta \mathrm{g}_{\mathrm{y}}, \mathrm{u}-\beta \mathrm{g}_{\mathrm{u}}\right)$, then the directional distance function at $(\mathrm{y}, \mathrm{u})$ point can be expressed as:

$$
\vec{D}_{0}\left(x, y, u ; g_{y},-g_{u}\right)=\sup \left\{\beta:\left(\mathrm{y}+\beta g_{y}, u-\chi g_{u}\right) \in P(x)\right\}
$$

In the formula, $\beta$ is the coefficient of the directional distance function, which reflects the multiple of the expansion or contraction of the directional vector in the combined output set. According to the homogeneity of Shephard directional distance function, there are:

$$
\vec{D}_{0}\left(x, y+\alpha g_{y}, u-\alpha g_{u} ; g\right)=\vec{D}_{0}(x, y, u ; g)-\alpha
$$

In the formula, $\alpha$ is the coefficient of the equation, which reflects the multiple of the expansion or contraction of the directional distance function. When the directional distance function is: $g=(y,-u)$, the directional distance function can be expressed as follows:

$$
\vec{D}_{0}(x, y, u ; y,-u)=\frac{1}{D_{0}(x, y, u)}-1
$$


According to the homogeneous property of the directional distance function, we can get: $\vec{D}_{0}(x, y, u ; y,-u)=\sup \left\{\beta: D_{0}(x, y+\beta y, u+\beta u) \leq 1\right\}$. After simplifying this formula, we can get that : $\sup \left\{\beta:(1+\beta) D_{0}(x, y, u) \leq 1\right\}=\sup \left\{\beta: 1 / D_{0}(x, y, u)-1\right\}$. According to Shephard directional distance function, we can take $g=(1,1)$, it is more convenient to determine the optimal combination of this point. Therefore, Shephard directional distance function is a special directional distance function. The Shephard directional distance function is extended to a general state, and the directional distance function is defined as:

$$
\vec{D}_{0}(x, y, u)=\min \left\{\lambda:\left(\frac{y}{\lambda}, \frac{u}{\lambda}\right) \in P(x)\right\}
$$

In the above formula: $\lambda$ is the combination coefficient of expected output and unexpected output, reflecting the multiple of expansion or contraction of expected output. This function inherits some properties of the input-output combination function $\mathrm{P}(\mathrm{x})$ and can quickly determine the optimal solution.

\subsection{Construction of Shadow Price Model}

Industrial Park production has expected and unexpected output and the unexpected output is mainly the emission of air pollutants with the expected output. To measure the emission loss of air pollutants from energy consumption in industrial parks, it is necessary to determine the shadow price of air pollutants. In order to construct the shadow price measurement model of air pollutants, it is necessary to construct the profit function of the output of production combination in industrial parks. If the price vector of input resources for industrial park production is: $p_{r}=\left(p_{r 1}, p_{r 2}, \cdots, p_{r n}\right)$, the corresponding expected output product price vector is: $p_{y}=\left(p_{y 1}, p_{y 2}, \cdots, p_{y l}\right)$, the price vector of unexpected output of air pollution emission is: $p_{u}=\left(p_{u 1}, p_{u 2}, \cdots, p_{u m}\right)$. If we use $\pi\left(p_{r}, p_{y}, p_{u}\right)$ to represent the profit function of combined production in industrial park, then there is:

$$
\pi\left(p_{r}, p_{y}, p_{u}\right)=\max _{x, y, u}\left\{y p_{y}-r p_{r}-u p_{u}:(y, u) \in P(x)\right\}
$$

Because the unexpected output of energy consumption in industrial parks is "three wastes", this paper mainly studies the environmental pollution losses caused by waste gas emissions. In the actual production process of industrial parks, the profit from production or the investment of environmental pollution control should be used to 
compensate the loss of environmental pollution. Therefore, the environmental pollution losses caused by air pollution emissions should be deducted from the expected revenue. According to the theory and method of shadow price, it can be clearly seen from Figure 2 that the combination distribution function composed of the expected output and unexpected output of industrial park production has the property of $P(x) \geq 0$. Actually, $(y, u) \in P(x)$ means that $\vec{D}_{0}\left(r, y, u ; g_{y}, g_{u}\right) \geq 0$. According to this property, the above formula is amended as follows:

$$
\pi\left(p_{r}, p_{y}, p_{u}\right)=\max _{r, y, u}\left\{y p_{y}-r p_{r}-u p_{u}: \vec{D}_{0}\left(r, y, u ; g_{y}, g_{u}\right) \geq 0\right\}
$$

If the output set $(y, u)$ of industrial park production is feasible under the given environmental and technological conditions, it is also feasible for the corresponding output to move on the directional vector $\left(g_{y}, g_{u}\right)$ to eliminate the inefficient output. That is: $(y, u) \in P(x)$. The directional vector expands or contracts in proportion to $\beta$. According to the theory of vector distance function, the following formula is valid:

$$
\left(y+\beta g_{y}, u-\beta g_{u}\right)=\left\{\left(y+\vec{D}_{0}(r, y, u ; g) \cdot g_{y}, u-\vec{D}_{0}(r, y, u ; g) \cdot g_{u}\right) \in P(x)\right\}
$$

Based on the analysis of the above two formulas, by comparing Formula (8) and Formula (7), and using the result of Formula (8) to modify Formula (7), the following modified profit function can be obtained:

$$
\pi\left(p_{r}, p_{y}, p_{u}\right) \geq\left(y p_{y}-r p_{r}-u p_{u}\right)+p_{y} \vec{D}_{0}(r, y, u ; g) \cdot g_{y}+p_{u} \vec{D}_{0}(r, y, u ; g) \cdot g_{u}
$$

The left side of the inequality represents the maximum profit of the industrial parks, and the right side reflects the additional profit after the elimination of inefficiency. That is to say, the maximum profit depends on the difference between the actual profit and the expenditure of eliminating inefficiency. This difference is the directional distance function. In order to maximize the profit, we must find the shortest distance from the point $(y, u)$ to the combination function $\mathrm{P}(\mathrm{x})$. The distance of the directional variable are expressed as:

$$
\vec{D}_{0}(r, y, u ; g) \leq \frac{\pi\left(p_{r}, p_{y}, p_{u}\right)-\left(y p_{y}-x p_{x}-u p_{u}\right)}{g_{y} p_{y}+g_{u} p_{u}}
$$

According to the definition of directional distance function, in order to effectively measure the shadow price of unexpected output, the above equation is transformed into an equation of extreme value problem. The specific model is as follows: 


$$
\vec{D}_{0}(r, y, u ; g)=\min \frac{\pi\left(p_{r}, p_{y}, p_{u}\right)-\left(y p_{y}-r p_{r}-u p_{u}\right)}{g_{y} p_{y}+g_{u} p_{u}}
$$

In this way, the shadow price measurement of the unexpected output is transformed into the extreme value problem. According to the extreme value theory and method, the partial derivatives of expected output variable $y$ and unexpected output variable $u$ in the formula are obtained, and the following formula is obtained by simplifying the calculation results of extreme value according to the derivation results:

$$
\left\{\begin{array}{l}
\frac{\partial \vec{D}_{0}(r, y, u ; g)}{\partial y}=\frac{-p_{y}}{g_{y} p_{y}+g_{u} p_{u}} \leq 0 \\
\frac{\partial \vec{D}_{0}(r, y, u ; g)}{\partial u}=\frac{p_{u}}{g_{y} p_{y}+g_{u} p_{u}} \geq 0
\end{array}\right.
$$

According to the calculation results of partial derivative of the above equation, we set the equation equal to zero and set up the system of equations. Because the expected output price is known, the shadow price $\left(p_{u}\right)$ of the unexpected pollutants in industrial parks can be determined by solving the simultaneous equations. The specific model is as follows:

$$
p_{u}=-p_{y} \frac{\partial \vec{D}_{0}(r, y, u ; g) / \partial u}{\partial \vec{D}_{0}(r, y, u ; g) / \partial y}
$$

When there are many kinds of expected output products and many kinds of unexpected output pollutants in the production activities of industrial parks, the price of the expected output products of type $\mathrm{i}$ is expressed in $p_{y i}$, and the shadow price of the unexpected output pollutants of type $\mathrm{j}$ is expressed in $p_{u j}$. Using extreme value theory and method, the partial derivatives of expected output variables and unexpected output variables in directional distance function are solved. After simplification, the following shadow price model is obtained:

$$
p_{u j}=-p_{y i} \frac{\partial \vec{D}_{0}(r, y, u ; g) / \partial u_{j}}{\partial \vec{D}_{0}(r, y, u ; g) / \partial y_{i}}=-p_{y i} \frac{\gamma_{j}+\sum_{k=1}^{K} \beta_{t k} u_{t k}+\sum_{l=1}^{L} \eta_{t l} r_{t l}+\sum_{h=1}^{H} \mu_{t h} u_{t h}}{\beta_{j}+\sum_{k=1}^{K} \beta_{t k} y_{t k}+\sum_{l=1}^{L} \delta_{t l} r_{t l}+\sum_{h=1}^{H} \mu_{t h} y_{t h}}
$$

The above formula is the shadow price model of energy consumption atmospheric pollution emissions and in industrial parks. As long as the parameters of the model are determined, it is convenient to use the statistical data, accounting statements and shadow price model of the industrial park to measure the shadow price of the energy 
consumption atmospheric pollutants discharged from the industrial park. Using the shadow price of air pollution emissions and the statistics of air pollution emissions, we can estimate the economic losses of air pollution emissions from industrial parks during a certain period of time.

\subsection{Estimation of Parameters of Shadow Price Measurement Model}

In fact, the shadow price model of energy consumption emission pollutants in industrial parks is constructed by using directional distance function. Therefore, the parameters of the directional distance function are consistent with those of the shadow price model and can be combined to estimate the parameters. In order to determine the parameters of the shadow price model of pollutants discharged from energy consumption waste gas emission in industrial parks, using Fare's method for reference, parameter linear programming method and extreme value theory were used to estimate the parameters (Fare et al., 2007). The parametric programming model for determining the parameters of the shadow price model of pollutants discharged from energy consumption waste gas emission in industrial parks is constructed as follows:

$$
\begin{aligned}
& f(r, y, u ; g)=\min \sum_{t=1}^{T} \sum_{n=1}^{N}\left\{\vec{D}_{0 t}\left(r_{t n}, y_{t n}, u_{t n} ; 1,1\right)-0\right\} \\
& \text { s.t.: }\left\{\begin{array}{l}
(1) \alpha_{i^{\prime}}=\alpha_{i^{\prime}}, i \neq i^{\prime}, j \neq j^{\prime}, k \neq k^{\prime}, \beta_{j}=\beta_{j^{\prime}}, \gamma_{k k^{\prime}}=\gamma_{k^{\prime} k} \\
(2) \beta-\sum_{j=1}^{J} \gamma_{j}=-1, \beta^{\prime}-\sum_{j=1}^{J} \mu_{j}=0, \delta_{i}-\sum_{j=1}^{J} \eta_{i j}=0, \sum_{j^{\prime}=1}^{J} \gamma_{j j^{\prime}}-\mu_{j}=0 \\
(3) \vec{D}_{0}^{t}\left(r_{t n}, y_{t n}, u_{t n} ; 1,1\right) \geq 0, \partial \vec{D}_{0}^{t}\left(r_{t n}, y_{t n}, u_{t n} ; 1,-1\right) / \partial y_{j n}^{t} \leq 0, \partial \vec{D}_{0}^{t}\left(r_{t n}, y_{t n}, u_{t n} ;, 1,-1\right) / \partial u_{k n}^{t} \geq 0
\end{array}\right.
\end{aligned}
$$

It can be seen that solving the objective function is actually solving the distance from a certain point of the combination of expected output and unexpected output to the combination function $\mathrm{P}(\mathrm{x})$. According to the theory of directional distance function, directional distance function has many specific forms. In order to determine the parameters easily, we choose the quadratic directional distance function to determine the parameters of the shadow price model, and select the directional vector $g=(1,1)$. From this point, the shortest distance, that is, the distance from $g=(1,1)$ to the extreme point, is found by expanding or contracting the unit multiple. If there are $\mathrm{k}$ production departments in the industrial park and the production cycle of the production department is expressed by $\mathrm{t}$, then the quadratic directional distance function of the kth production department in the production cycle $\mathrm{t}$ can be 
expressed as follows:

$$
\begin{aligned}
\partial \vec{D}_{0}\left(r_{i t}, y_{i t}, u_{i t} 1,1\right)= & \alpha_{0}+\sum_{\mathrm{i}=1}^{\mathrm{I}} \alpha_{\mathrm{i}} r_{i t}+\sum_{j=1}^{J} \beta_{j} y_{j t}+\sum_{k=1}^{K} \gamma_{k} u_{k t} \\
& +\frac{1}{2} \sum_{\mathrm{i}=1}^{\mathrm{I}} \sum_{\mathrm{i}^{\prime}=1}^{\mathrm{I}} \alpha_{\mathrm{ii}} r_{i t} r_{i^{\prime} t}+\frac{1}{2} \sum_{\mathrm{j}=1}^{\mathrm{J}} \sum_{\mathrm{j}^{\prime}=1}^{\mathrm{J}} \beta_{\mathrm{j} j^{\prime}} y_{j t} y_{j^{\prime} t}++\frac{1}{2} \sum_{\mathrm{k}=1}^{\mathrm{K}} \sum_{\mathrm{k}^{\prime}=1}^{\mathrm{K}} \gamma_{\mathrm{kk}} u_{k t} u_{k^{\prime} t} \\
& +\sum_{\mathrm{i}=1}^{\mathrm{I}} \sum_{\mathrm{j}=1}^{\mathrm{J}} \delta_{\mathrm{ij}} r_{j t} y_{j t}+\sum_{\mathrm{i}=1}^{\mathrm{I}} \sum_{\mathrm{k}=1}^{\mathrm{K}} \eta_{\mathrm{ik}} r_{k t} u_{k t}+\sum_{\mathrm{j}=1}^{\mathrm{J}} \sum_{\mathrm{k}=1}^{\mathrm{K}} \mu_{\mathrm{jk}} y_{k t} u_{k t}
\end{aligned}
$$

In the above formula, $r_{i t}$ represents the $\mathrm{i}_{\mathrm{th}}$ input resources in the period $\mathrm{t}$. Four specific investment forms are selected in the study: assets, manpower, energy and environmental pollution control investment; $y_{i t}$ is the $i_{\text {th }}$ expected output in the period t. In this study, we choose a specific form of the gross output value of industrial parks; $u_{i t}$ represents the $\mathrm{i}_{\mathrm{th}}$ unexpected output in the period t. Six specific forms, including $\mathrm{SO}_{2}, \mathrm{NO}_{2}, \mathrm{CO}, \mathrm{O}_{3}, \mathrm{PM}_{2.5}$ and $\mathrm{PM}_{10}$, were selected in the study. Other letters and serial Numbers had the same meaning.

There are three basic constraints in the parametric programming model. The constraint condition (1) is a second-order symmetry condition, which specify the parametric symmetry of the equation and facilitate the solution of parametric programming. The constraint condition (2) is the translation property of the directional distance function. According to the homogeneity of the Shephard directional distance function, the directional distance function can be simplified as follows:

$$
\vec{D}_{0}^{t}\left(r_{t n}, y_{t n}+\alpha g_{y}, u_{t n}-\alpha g_{u} ; 1,1\right)=\vec{D}_{0}\left(r_{t n}, y_{t n}, u_{t n} ; 1.1\right)-\alpha
$$

In order to determine the parameters of directional distance function, the first and second order partial derivatives are obtained on both sides of the equation according to the extreme value theory and method, and the parameters of directional distance function can be estimated by using the constraint condition (2). According to the results of partial derivatives, the following equations can be obtained:

$$
\left\{\begin{array}{l}
\frac{\partial D_{0}^{t}\left(r_{t n}, y_{t n}+\alpha, u_{t n}-\alpha ; 1,-1\right)}{\partial\left(y_{t n}+\alpha\right)}-\frac{\partial D_{0}^{t}\left(r_{t n}, y_{t n}+\alpha, u_{t n}-\alpha ; 1,-1\right)}{\partial\left(u_{t n}-\alpha\right)}=-1 \Rightarrow \beta-\sum_{j=1}^{J} \gamma_{j}=-1 \\
\frac{\partial\left(D_{0}^{t}\right)^{2}\left(r_{t n}, y_{t n}+\alpha, u_{t n}-\alpha ; 1,-1\right)}{\partial\left(y_{t n}+\alpha\right)^{2}}-\frac{\partial D_{0}^{t}\left(r_{t n}, y_{t n}+\alpha, u_{t n}-\alpha ; 1,-1\right)}{\partial\left(y_{t n}+\alpha\right) \partial\left(u_{t n}-\alpha\right)}=0 \Rightarrow \beta^{\prime}-\sum_{j=1}^{J} \mu_{j}=0 \\
\frac{\partial D_{0}^{t}\left(r_{t n}, y_{t n}+\alpha, u_{t n}-\alpha ; 1,-1\right)}{\partial r_{t n} \partial\left(y_{t n}+\alpha\right)}-\frac{\partial D_{0}^{t}\left(r_{t n}, y_{t n}+\alpha, u_{t n}-\alpha ; 1,-1\right)}{\partial r_{t n} \partial\left(u_{t n}-\alpha\right)}=0 \Rightarrow \delta_{i}-\sum_{j=1}^{J} \eta_{i j}=0 \\
\frac{\partial D_{0}^{t}\left(r_{t n}, y_{t n}+\alpha, u_{t n}-\alpha ; 1,-1\right)}{\partial\left(u_{t n}-\alpha\right)-\partial\left(y_{t n}+\alpha\right)}-\frac{\partial\left(D_{0}^{t}\right)^{2}\left(r_{t n}, y_{t n}+\alpha, u_{t n}-\alpha ; 1,-1\right)}{\partial\left(u_{t n}-\alpha\right)^{2}}=0 \Rightarrow \sum_{j^{\prime}=1}^{J} \gamma_{j j^{\prime}}-\mu_{j}=0
\end{array}\right.
$$

The constraint condition (3) of the parametric programming equation is the stipulation of non-negative and 
monotonic characteristics of the directional distance function. The setting of monotonic characteristics can make the shadow price of pollutants discharged from industrial parks negative. This constraint condition is also an important condition for solving parametric programming equation. Based on the above analysis results and related theories, this constraint condition can be expressed as follows:

$$
\left\{\begin{array}{l}
(1) \partial \vec{D}_{0}\left(r_{i t}, y_{i t}, u_{i t} ; 1,1\right)=(15) \text { 式 } \geq 0 \\
(2) \partial \vec{D}_{0}^{t}\left(r_{t n}, y_{t n}, u_{t n} ; 1,-1\right) / \partial y_{j n}^{t}=\beta+\beta^{\prime} y_{k}+\sum_{i=1}^{I} \delta_{i} r_{i k}+\sum_{j=1}^{J} \mu_{j} u_{j k} \leq 0, \\
(3) \partial \vec{D}_{0}^{t}\left(r_{t n}, y_{t n}, u_{t n} ; 1,-1\right) / \partial u_{k n}^{t}=\gamma_{j}+\frac{1}{2} \sum_{j^{\prime}}^{J} \gamma_{j j^{\prime}} u_{j^{\prime} k}+\sum_{i=1}^{I} \eta_{i j} r_{i k}+\mu_{j} y_{k} \geq 0
\end{array}\right.
$$

For constraint condition (1) in the above equation, the directional distance function is represented as a quadratic function by Chambers method, and the quadratic function is used as a second-order approximate estimation of a production technique. Second Order Approximation method is used to estimate the parameters of the above directional distance function. That is, the parameters of directional distance function are determined by solving the partial derivative of quadratic function. The specific results are shown in the following expressions:

$$
\left\{\begin{array}{l}
\partial \vec{D}_{0}\left(r_{k}, y_{k}, u_{k} ; g_{y}, g_{u}\right) / \partial r_{i k}=\alpha_{i} \\
\partial \vec{D}_{0}\left(r_{k}, y_{k}, u_{k} ; g_{y}, g_{u}\right) / \partial y_{k}=\beta \\
\partial \vec{D}_{0}\left(r_{k}, y_{k}, u_{k} ; g_{y}, g_{u}\right) / \partial u_{j k}=\gamma_{j} \\
\partial \vec{D}_{0}\left(r_{k}, y_{k}, u_{k} ; g_{y}, g_{u}\right) / \partial r_{i k} \partial r_{i^{\prime} k}=\alpha_{i i^{\prime}} \\
\partial \vec{D}_{0}^{2}\left(r_{k}, y_{k}, u_{k} ; g_{y}, g_{u}\right) / \partial y_{k}^{2}=\beta^{\prime} \\
\partial \vec{D}_{0}\left(r_{k}, y_{k}, u_{k} ; g_{y}, g_{u}\right) / \partial u_{j k} \partial u_{j^{\prime} k}=\gamma_{j j^{\prime}} \\
\partial \vec{D}_{0}\left(r_{k}, y_{k}, u_{k} ; g_{y}, g_{u}\right) / \partial r_{i k} y_{k}=\delta_{i} \\
\partial \vec{D}_{0}\left(r_{k}, y_{k}, u_{k} ; g_{y}, g_{u}\right) / \partial r_{i k} u_{j k}=\eta_{i j} \\
\partial \vec{D}_{0}\left(r_{k}, y_{k}, u_{k} ; g_{y}, g_{u}\right) / \partial y_{k} u_{j k}=\mu_{j}
\end{array}\right.
$$

By using the objective function and constraints of the above analysis, the parametric programming equation (15) can be easily solved. By solving the parametric equation, the parameters of the shadow price model of energy consumption emission pollutants in industrial parks can be determined. By substituting the determined parameters into the shadow price model (14), the shadow price model can be used to calculate the shadow price of pollutants emitted from energy consumption waste gas emission in industrial parks. It is convenient to calculate the emission 
loss of air pollutants by using the determined shadow price of air pollutants and pollutant statistics.

\section{Results}

\subsection{Overview of MV Industrial Park in Nanjing}

Nanjing MV Industrial Park is located in Jiangning Economic and Technological Development Zone, Nanjing City, Jiangsu Province, with an area of 52.98 square kilometers. There are 52 production enterprises in the industrial park. By the end of 2018, there were 32.632 thousand employees, 4.21856 billion yuan of registered capital and 10.63628 billion yuan of fixed assets investment. The output value was 15.12645 billion yuan and the profit and tax was 1.53218 billion yuan. Nanjing MV Industrial Park was founded in 1998 and realized planned production capacity in 2001. Most of the enterprises in the park are energy-consuming enterprises. According to the statistics of the industrial park, the production of enterprises in the park is increasing while creating the total output value. The Nanjing MV industrial park is mainly characterized by air pollution caused by waste gas emissions, which include $\mathrm{SO}_{2}, \mathrm{NO}_{2}, \mathrm{CO}, \mathrm{O}_{3}, \mathrm{PM}_{2.5}$ and $\mathrm{PM}_{10}$. In order to measure the economic losses caused by energy consumption emission pollutants in Nanjing MV Industrial Park, the basic input-output data of Nanjing MV Industrial Park from 2011 to 2018 are collected as detailed in Table 1.

Table 1 Statistics Table of Basic Input and Output Data of Nanjing MV Industrial Park from 2011 to 2018

\begin{tabular}{|c|c|c|c|c|c|c|c|c|}
\hline Indicator Name & 2011 & 2012 & 2013 & 2014 & 2015 & 2016 & 2017 & 2018 \\
\hline Total output value (RMB 10,000） & 798632 & 821827 & 882718 & 912739 & 953681 & 1085427 & 1213546 & 1512645 \\
\hline Investment in Fixed Assets（RMB 10,000） & 714846 & 782817 & 831718 & 882618 & 912817 & 942617 & 963827 & 106.36 \\
\hline Energy input (10,000 tons of standard coal) & 1848.36 & 2462.37 & 2893.37 & 3468.29 & 3946.28 & 4456.32 & 4848.25 & 5563.37 \\
\hline Investment in Environmental Pollution Control (RMB 10,000) & 13536 & 15216 & 16927 & 18216 & 18925 & 20162 & 23627 & 28455 \\
\hline $\mathrm{SO}_{2}$ emissions (tons) & 8535 & 7795 & 7388 & 6931 & 6740 & 6571 & 6354 & 6147 \\
\hline $\mathrm{O}_{3}$ emissions (tons) & 105 & 122 & 142 & 165 & 185 & 213 & 268 & 282 \\
\hline $\mathrm{PM}_{25}$ emissions (tons) & 1057 & 1128 & 1386 & 1475 & 1567 & 1656 & 1825 & 1897 \\
\hline $\mathrm{PM}_{10}$ emissions (tons) & 894 & 983 & 1026 & 1217 & 1369 & 1408 & 1537 & 1656 \\
\hline
\end{tabular}

Sources: According toNanjing MV Industrial Park 2011-2018 "Financial Statements" and "Environmental Status Bulletin" statistical datacollation 


\subsection{Calculation of Shadow Price of Pollutants Emitted from Waste Gas}

According to the analysis results of shadow price model and parameter determination method, the size of parameters of directional distance function depends on the number and status of input and output variables of production decision system. In this paper, we choose four input variables: fixed assets, number of employees, energy consumption, investment in environmental pollution control. The total output value is the expected output variable; Six output variables of unexpected energy consumption waste gas emission, including $\mathrm{SO}_{2}$ emissions, $\mathrm{NO}_{2}$ emissions, $\mathrm{CO}$ emissions, $\mathrm{O}_{3}$ emissions, $\mathrm{PM}_{2.5}$ emissions and $\mathrm{PM}_{10}$ emissions. According to the formula (15) - (20), 98 parameters need to be determined to calculate the shadow price of the undesirable output of formula (14). Using formula (18) and relevant statistical data of MV Industrial Park in Nanjing from 2011 to 2018, the estimated results of all parameters are shown in Table 2.

Table 2 Parameter estimation results of directional distance function

\begin{tabular}{|c|c|c|c|c|c|c|c|c|c|}
\hline Parameter & Estimated value & Parameter & Estimated value & Parameter & Estimated value & Parameter & Estimated value & Parameter & Estimated value \\
\hline$\alpha_{0}$ & -0.1138 & $\alpha_{43}$ & -0.1295 & $\gamma_{24}$ & -0.1851 & $\gamma_{65}$ & -0.1015 & $\eta_{32}$ & 0.0975 \\
\hline$\alpha_{1}$ & 0.2016 & $\alpha_{44}$ & -0.1214 & $\gamma_{35}$ & -0.1015 & $\gamma_{66}$ & -0.1192 & $\eta_{33}$ & 0.1128 \\
\hline$\alpha_{2}$ & 0.3227 & $\beta_{1}$ & 0.1124 & $\gamma_{36}$ & 0.1523 & $\delta_{11}$ & 0.4217 & $\eta_{34}$ & -0.3482 \\
\hline$\alpha_{3}$ & 0.1015 & $\beta_{11}$ & 0.4262 & $\gamma_{41}$ & 0.0657 & $\delta_{21}$ & 0.3616 & $\eta_{35}$ & -0.6217 \\
\hline$\alpha_{4}$ & -0.4013 & $\gamma_{1}$ & 0.2131 & $\gamma_{42}$ & 0.1837 & $\delta_{31}$ & -0.3224 & $\eta_{36}$ & 0.0983 \\
\hline$\alpha_{11}$ & -0.1135 & $\gamma_{2}$ & -0.1072 & $\gamma_{43}$ & 0.1227 & $\delta_{41}$ & 0.2816 & $\eta_{41}$ & -0.2178 \\
\hline$\alpha_{12}$ & 0.2167 & $\gamma_{3}$ & 0.2857 & $\gamma_{44}$ & 0.1675 & $\eta_{11}$ & -0.0416 & $\eta_{42}$ & 0.2073 \\
\hline$\alpha_{13}$ & 0.2057 & $\gamma_{4}$ & -0.1636 & $\gamma_{45}$ & 0.1889 & $\eta_{12}$ & -0.0672 & $\eta_{43}$ & 0.1827 \\
\hline$\alpha_{14}$ & -0.1228 & $\gamma_{5}$ & -0.2124 & $\gamma_{46}$ & 0.2107 & $\eta_{13}$ & 0.0925 & $\eta_{44}$ & 0.3016 \\
\hline$\alpha_{21}$ & 0.0448 & $\gamma_{6}$ & 0.2122 & $\gamma_{51}$ & 0.2078 & $\eta_{14}$ & 0.1066 & $\eta_{45}$ & 0.0923 \\
\hline$\alpha_{22}$ & 0.1627 & $\gamma_{11}$ & 0.3016 & $\gamma_{52}$ & 0.1886 & $\eta_{15}$ & 0.0886 & $\eta_{46}$ & -0.8621 \\
\hline$\alpha_{23}$ & -0.2372 & $\gamma_{12}$ & 0.2458 & $\gamma_{53}$ & 0.0985 & $\eta_{16}$ & -0.0768 & $\mu_{11}$ & 0.0627 \\
\hline$\alpha_{24}$ & -0.3327 & $\gamma_{13}$ & 0.2638 & $\gamma_{54}$ & 0.0674 & $\eta_{21}$ & 0.0547 & $\mu_{12}$ & 0.0875 \\
\hline$\alpha_{31}$ & 0.2751 & $\gamma_{14}$ & -0.2236 & $\gamma_{55}$ & -0.0768 & $\eta_{22}$ & 0.0268 & $\mu_{13}$ & 0.1027 \\
\hline$\alpha_{32}$ & 0.3016 & $\gamma_{15}$ & -0.1827 & $\gamma_{56}$ & -0.0786 & $\eta_{23}$ & 0.1027 & $\mu_{14}$ & -0.7891 \\
\hline$\alpha_{33}$ & 0.0981 & $\gamma_{16}$ & 0.2151 & $\gamma_{61}$ & 0.0864 & $\eta_{24}$ & -0.1926 & $\mu_{15}$ & 0.0527 \\
\hline$\alpha_{34}$ & -0.2138 & $\gamma_{21}$ & 0.1625 & $\gamma_{62}$ & 0.0579 & $\eta_{25}$ & 0.0279 & $\mu_{16}$ & 0.0602 \\
\hline$\alpha_{41}$ & -0.1826 & $\gamma_{22}$ & 0.2016 & $\gamma_{63}$ & 0.0874 & $\eta_{26}$ & 0.0653 & & \\
\hline$\alpha_{42}$ & 0.2136 & $\gamma_{23}$ & 0.3127 & $\gamma_{64}$ & 0.1092 & $\eta_{31}$ & -0.0753 & & \\
\hline
\end{tabular}

Based on the research and design, the parameters of the directional distance function of the shadow price model for sewage discharge in Nanjing MV Industrial Park are estimated. By substituting the parameters of the estimated directional distance function into formula (14), the shadow price model can be used to measure the shadow price of pollutants discharged from industrial parks in 2011-2018. The calculation results are detailed in Table 3. 
Table 3 Shadow Price Table for Energy Consumption Emission Pollutants of Nanjing MV Industrial Park, 2011-2018

\begin{tabular}{|c|c|c|c|c|c|c|}
\hline $\begin{array}{c}\text { No. } \\
\text { (year) }\end{array}$ & $\begin{array}{c}\mathrm{SO}_{2} \\
(10,000 \text { yuan/ton })\end{array}$ & $\begin{array}{c}\mathrm{NO}_{2} \\
(10,000 \text { yuan/ton })\end{array}$ & $\begin{array}{c}\mathrm{CO} \\
(10,000 \mathrm{yuan} / \text { ton })\end{array}$ & $\begin{array}{c}\mathrm{O}_{3} \\
(10,000 \text { yuan/ton })\end{array}$ & $\begin{array}{c}\mathrm{PM}_{25} \\
(10,000 \text { yuan/ton })\end{array}$ & $\begin{array}{c}\mathrm{PM}_{10} \\
(10,000 \text { yuan/ton })\end{array}$ \\
\hline 2011 & 4.5626 & 3.5672 & 0.7057 & 3.0982 & 3.3327 & 2.8726 \\
\hline 2013 & 4.7932 & 3.8794 & 0.7348 & 3.3839 & 3.6578 & 3.0328 \\
\hline 2014 & 4.8152 & 3.9875 & 0.7562 & 3.5129 & 3.7859 & 3.1827 \\
\hline 2016 & 5.0417 & 4.1635 & 0.7848 & 3.7627 & 4.0628 & 3.3926 \\
\hline 2017 & 4.9021 & 4.3625 & 0.8128 & 3.8932 & 4.1686 & 3.5671 \\
\hline 2018 & 5.0965 & 4.5266 & 0.8267 & 3.9837 & 4.2369 & 3.6872 \\
\hline
\end{tabular}

\subsection{Measurement of Environmental Pollution Loss from Waste Gas Emission}

The environmental pollution loss caused by energy consumption waste gas emission in industrial parks is equal to the cumulative sum of pollutant emissions from waste gas emissions and corresponding shadow prices. Because industrial parks have statistical data on pollutants discharged from energy consumption waste gas emission, the key to measure environmental pollution losses from waste gas discharge is to determine the shadow price of pollutants. According to the above measurement, the shadow price of pollutants emitted from energy consumption waste gas emission of MV Industrial Park in Nanjing and the relevant statistical data are obtained. The calculation results of environmental pollution losses from energy consumption waste gas emission of the park are detailed in Table 4.

Table 4 Calculating table of environmental pollution losses from waste gas emission in Nanjing MV Industrial Park

\begin{tabular}{|c|c|c|c|c|c|c|c|c|c|}
\hline & Indicator Name & 2011 & 2012 & 2013 & 2014 & 2015 & 2016 & 2017 & 2018 \\
\hline $\mathrm{SO}_{2}$ & Emissions (tons) & 8535 & 7795 & 7388 & 6931 & 6740 & 6571 & 6354 & 6147 \\
\hline Pollution & Shadow price (10,000 yuan/ton) & 4.5626 & 4.6932 & 4.7932 & 4.8152 & 4.9421 & 5.0417 & 4.9021 & 5.0965 \\
\hline Loss & Total economic losses (10,000 yuan) & 38942 & 36583 & 35412 & 33374 & 33310 & 33129 & 31148 & 31328 \\
\hline $\mathrm{NO}_{2}$ & Emissions (tons) & 6639 & 6519 & 6242 & 6047 & 5762 & 5692 & 5567 & 5419 \\
\hline \multirow{2}{*}{$\begin{array}{c}\text { Pollution } \\
\text { Loss }\end{array}$} & Shadow price (10,000 yuan/ton) & 3.5672 & 3.6823 & 3.8794 & 3.9875 & 4.0565 & 4.1635 & 4.3625 & 4.5266 \\
\hline & Total economic losses (10,000 yuan) & 23683 & 24005 & 24215 & 24112 & 23374 & 23699 & 24286 & 24530 \\
\hline \multirow{3}{*}{$\begin{array}{c}\mathrm{NO}_{2} \\
\text { Pollution } \\
\text { Loss }\end{array}$} & Emissions (10,000 tons) & 699 & 931 & 1094 & 1311 & 1492 & 1685 & 1833 & 2103 \\
\hline & Shadow price (10,000 yuan/ton) & 0.7057 & 0.7237 & 0.7348 & 0.7562 & 0.7656 & 0.7848 & 0.8128 & 0.8267 \\
\hline & Total economic losses (10,000 yuan) & 493 & 674 & 804 & 991 & 1142 & 1322 & 1490 & 1739 \\
\hline $\mathrm{O}_{3}$ & Emissions (tons) & 105 & 122 & 142 & 165 & 185 & 213 & 268 & 282 \\
\hline \multirow{2}{*}{$\begin{array}{c}\text { Pollution } \\
\text { Loss }\end{array}$} & Shadow price (10,000 yuan/ton) & 3.0982 & 3.2839 & 3.3839 & 3.5129 & 3.6352 & 3.7627 & 3.8932 & 3.9837 \\
\hline & Total economic losses (10,000 yuan) & 325 & 401 & 481 & 580 & 673 & 801 & 1043 & 1123 \\
\hline $\mathrm{PM}_{25}$ & Emissions (tons) & 1057 & 1128 & 1386 & 1475 & 1567 & 1656 & 1825 & 1897 \\
\hline \multirow{2}{*}{$\begin{array}{c}\text { Pollution } \\
\text { Loss }\end{array}$} & Shadow price (10,000 yuan/ton) & 3.3327 & 3.5461 & 3.6578 & 3.7859 & 3.9865 & 4.0628 & 4.1686 & 4.2369 \\
\hline & Total economic losses (10,000 yuan) & 3523 & 4000 & 5070 & 5584 & 6247 & 6728 & 7608 & 8037 \\
\hline $\mathrm{PM}_{10}$ & Emissions (tons) & 894 & 983 & 1026 & 1217 & 1369 & 1408 & 1537 & 1656 \\
\hline Pollution & Shadow price (10,000 yuan/ton) & 2.8726 & 2.9762 & 3.0328 & 3.1827 & 3.3219 & 3.3926 & 3.5671 & 3.6872 \\
\hline Loss & Total economic losses (10,000 yuan) & 2568 & 2926 & 3112 & 3873 & 4548 & 4777 & 5483 & 6106 \\
\hline
\end{tabular}


Using the shadow price model of pollutants discharged from energy consumption waste gas emission in industrial parks, the environmental pollution losses of energy consumption waste gas emission from Nanjing MV industrial parks are estimated. The detailed measurement results are shown in Table 5.

Table 5 Measurement results of pollution loss from waste gas emission in Nanjing MV Industrial Park

\begin{tabular}{lcccccccc}
\hline NO. (year) & 2011 & 2012 & 2013 & 2014 & 2015 & 2016 & 2017 & 2018 \\
\hline $\begin{array}{l}\text { Environmental Pollution Loss from Exhaust Gas } \\
\text { Discharge (10,000 yuan) }\end{array}$ & 69049 & 67956 & 68334 & 67591 & 68205 & 69181 & 69527 & 71142 \\
\hline
\end{tabular}

From the above table, it can be seen that after considering $\mathrm{CO}, \mathrm{O}_{3}$ and $\mathrm{PM}$, the results of environmental pollution loss measurement have been significantly improved. If other pollutants are considered, the environmental pollution loss will also be increased.

\section{Discussion}

\subsection{Analysis of measurement results}

In order to analyze the measurement results of environmental pollution losses from energy consumption waste gas emission in Nanjing MV Industrial Park, the environmental pollution losses and its growth rate are drawn in Cartesian coordinate system. The details are shown in Figure 4.

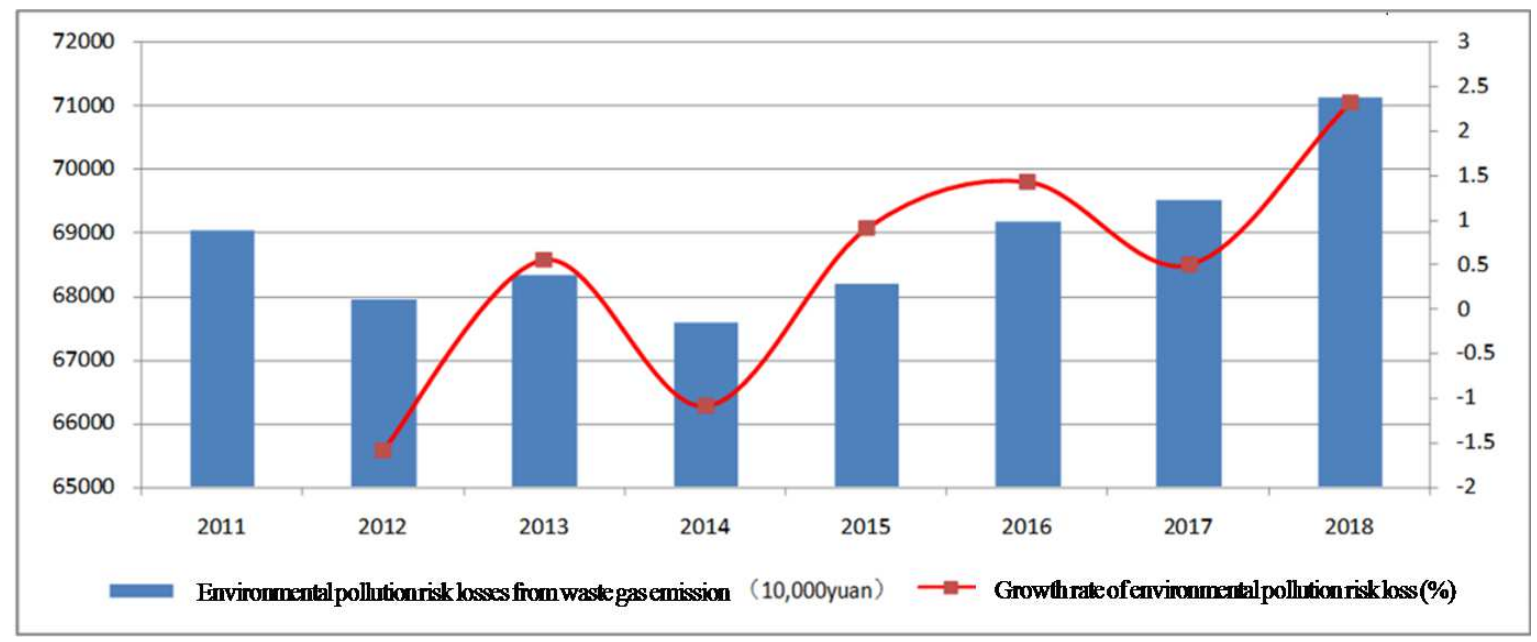

FIG.4. Environmental Pollution Loss and Growth Rate Trend Chart of waste gas emission in Nanjing MV Industrial Park

From the above figure, it can be clearly seen that the trend of environmental pollution loss of energy consumption waste gas emission in Nanjing MV Industrial Park can be divided into two different stages of development. The first stage is from 2011 to 2014, during which the environmental pollution loss of energy 
consumption waste gas emission of Nanjing MV Industrial Park shows a downward trend; the second stage is from 2014 to 2018. During this stage, the environmental pollution loss of energy consumption waste gas emission of Nanjing MV Industrial Park shows an upward trend. Comprehensive analysis shows that the environmental pollution loss of energy consumption waste gas emission in Nanjing MV Industrial Park presents a "U" trend, which indicates that the environmental pollution control effect of energy consumption waste gas emission in the industrial park is not good, and the specific environmental pollution control effect will be discussed in the measurement results. From the analysis of the changing trend of the growth rate of environmental pollution loss, the growth rate of environmental pollution loss of energy consumption waste gas emission in Nanjing MV Industrial Park has obvious volatility, and the overall change trend shows a trend of first decreasing and then rising, with the characteristics of rising fluctuation.

\subsection{Discussion on Measuring Results}

It is found that the shadow price model can be used to effectively measure the environmental pollution loss of energy consumption waste gas emission in industrial parks. This method can be can be suitable for a variety of environmental pollution loss measurement. Moreover, through the analysis of the results of the environmental pollution measurement of energy consumption waste gas emission from industrial parks, it is possible to clarify the changing rules of environmental pollution losses from energy consumption waste gas emission and the main environmental problems in the development of industrial parks. Based on the results of the measurement analysis, the paper puts forward some suggestions to improve the control of energy consumption waste gas emission in industrial parks and promote the continuous reduction of environmental pollution losses.

(1) The key to promote the sustainable reduction of environmental pollution losses from energy consumption waste gas emission in industrial parks is to seize the key points. In order to explore an effective way to continuously reduce the environmental pollution losses caused by energy consumption waste gas emission in industrial parks, the composition and variation of the environmental pollution measurement results of energy consumption waste gas emission in industrial parks should be analyzed. In Cartesian coordinate system, the composition and change trend of 
atmospheric environmental pollution losses are drawn. The specific content and changing rules are detailed in Figure 5.

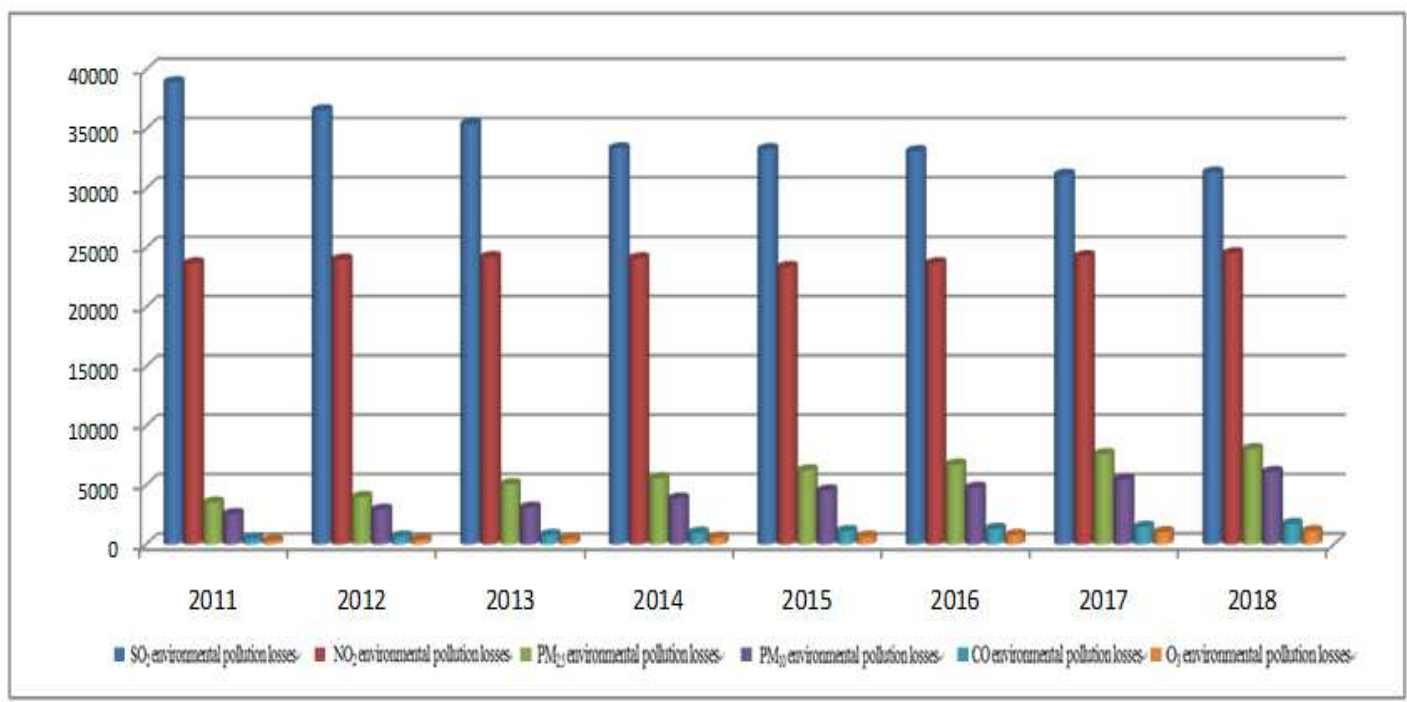

Fig.5.Environmental Pollution Loss Composition and Change Chat of Waste gas emission in MV Industial Park of Nanjing

As can be seen from the above figure, there is a great imbalance in the composition of environmental pollution losses due to energy consumption waste gas emission of MV Industrial Park in Nanjing. Therefore, the focus of environmental pollution control should be on both ends. That is, special attention should be paid to the relatively high proportion of environmental pollution losses. In other words, attention should be paid to the reduction of $\mathrm{SO}_{2}$ environmental pollution losses and $\mathrm{NO}_{2}$ environmental pollution losses, so as to achieve a significant improvement in the effectiveness of environmental pollution control. At the same time, we should also pay attention to the relatively low proportion of environmental pollution losses, that is, to pay attention to the control of environmental pollution losses of $\mathrm{CO}$ and $\mathrm{O} 3$, so that the relatively low proportion of environmental pollution losses is kept to a minimum, so as to maintain the stability of environmental pollution losses.

(2) Reducing the total environmental pollution loss of energy consumption waste gas emission is the ultimate goal of the research. No matter from which aspect to reduce environmental pollution losses, the ultimate goal is to reduce the total losses. Therefore, the core of the research is to pay attention to the research objectives. In order to explore an effective way to achieve the research objectives, the total environmental pollution losses and components of energy consumption waste gas emission of Nanjing MV Industrial Park are plotted by radar. The specific contents are detailed in Figure 6. 


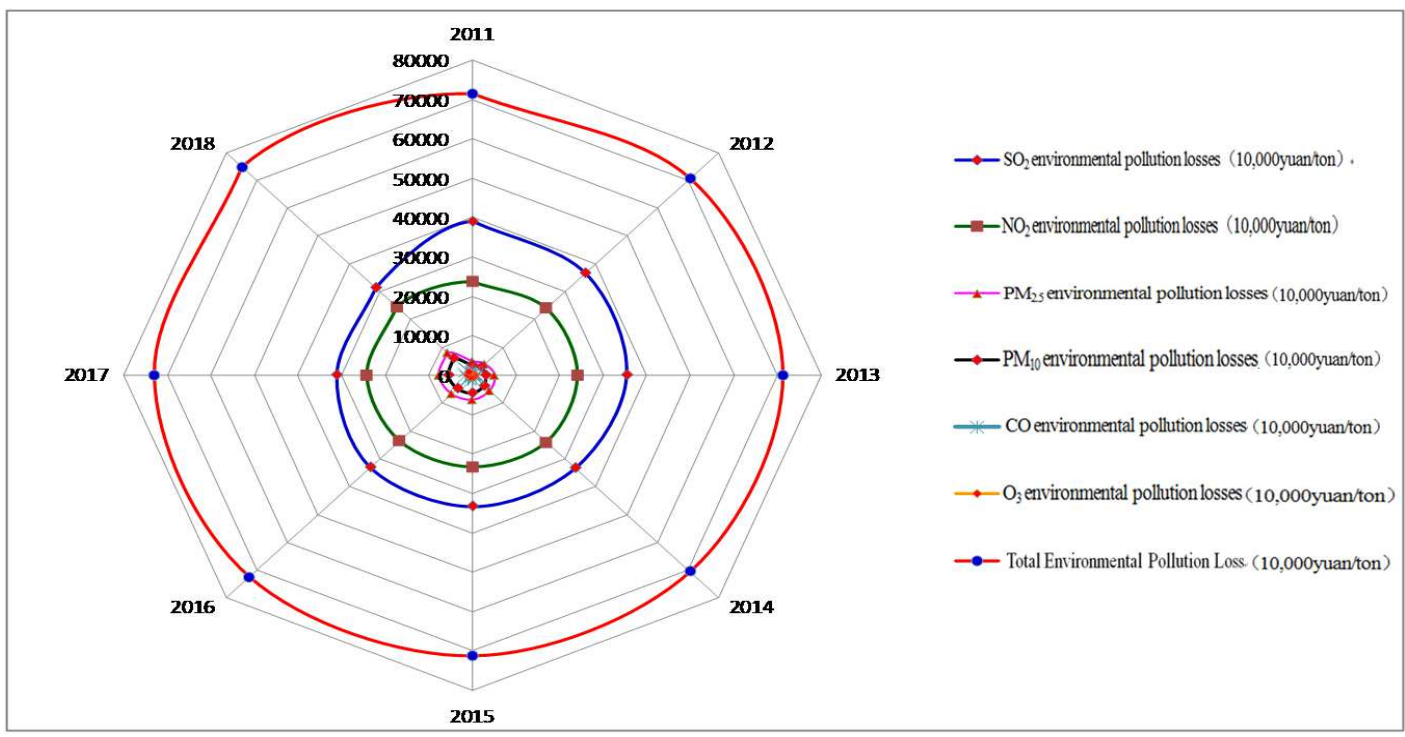

FIG6. Radar Map of Environmental Pollution Loss Measurement Result of waste gas emission in Nanjing MV Industrial Park

From the above figure, it can be clearly seen that there is an imbalance in the composition of environmental pollution losses caused by energy consumption waste gas emission of Nanjing MV Industrial Park. The environmental pollution loss of energy consumption waste gas emission in the industrial park is mainly caused by $\mathrm{SO}_{2}$ emission and $\mathrm{NO}_{2}$ emission. Therefore, conventional air pollution loss measurement only focuses on important factors. However, the environmental pollution loss caused by energy consumption waste gas emission in industrial parks is the result of the comprehensive effect of all waste gas emission pollutants. In addition, with the change of the production environment of industrial parks, the factors affecting the environmental pollution loss of waste gas emissions will change or shift, and some currently unimportant influencing factors may become important to affect the environmental pollution loss. Therefore, although the principle of importance is effective and efficient under certain conditions, policy makers and managers should pay attention to research goals and changes in the environment and conditions. Only by choosing an effective strategy according to the actual situation can the environmental pollution losses caused by energy consumption waste gas emission in industrial parks be continuously reduced.

\section{Conclusions}

The measurement and application of environmental pollution losses from energy consumption waste gas emission 
in industrial parks is an important research topic. In order to explore an effective method for measuring environmental pollution losses from energy consumption waste gas emission in industrial parks, based on background analysis and literature review, this paper studies the construction of directional distance function and the shadow price measurement model of energy consumption waste gas emission, and determines the relative parameters. In order to verify the validity of the shadow price model, a case study of Nanjing MV Industrial Park was selected to study the shadow price model of pollutants discharged from energy consumption waste gas emission in this park. On this basis, the effective ways to reduce the loss of energy consumption waste gas emission in industrial parks are discussed. Because of the complexity of environmental pollution loss measurement of energy consumption waste gas emission in industrial parks, there are still some limitations in the research process in this paper, such as relatively short data period, relatively few influencing factors to be considered in the construction of shadow price model, simplified solution of parametric programming model, and so on, which all affect the effectiveness of the research results. Therefore, in the future research of this topic, we should start from overcoming these limitations to carry out in-depth research, and promote the continuous improvement of the research effect of this topic.

\section{Abbreviations}

MV: The name of the target company is not authorized to be expressed in letters; AHP: Analytic Hierarchy Process; CI: Negative Means of Other Characteristic Roots beyond the Maximum Characteristic Roots; RI: Random consistency mean.

\section{Acknowledgements}

The research data were provided by Nanjing Statistical Bureau and Nanjing MV Industrial Park Management Committee. This paper is the research result of the Chinese Social Science Foundation Project (19BJL035).

\section{Authors' contributions}

Under the guidance of Professor Sun Tao, this paper was written by Dr. Xiuyan Han and translated into English by Ms. Tianyi Cao. Professor Tao Sun designed the paper and participated in the modeling. Ms. Tianyi Cao also participated in the technical processing of research data and related calculations. The results of this paper are innovative and have important theoretical significance and practical value.

\section{Funding}

This work has received funding from the general project of national social science foundation of China: "Research on mechanism and supportive polices of environmental pollution cooperative governance in the process of regional integration development of the Yangtze river delta"(Approval number: 19BJL035). 


\section{Availability of data and materials}

The data and materials in this paper are included in the paper and the annex.

\section{Ethics approval and consent to participate}

Not applicable, since the present study is a re-evaluation of existing data.

\section{Consent for publication}

Not applicable

\section{Competing interests}

Professor Tao Sun is employed by Nanjing University of Aeronautics and Astronautics. Xiuyan Han is a doctoral student and Tianyi Cao is a master. This paper is the research result of Professor Tao Sun's project of China Social Science Foundation. Therefore, there is no competitive interest between this article and any person or organization.

\section{Author details}

Authors: Xiuyan Han (1974-), Women, Born in Jiamusi of Heilongjiang province, PhD candidate, College of Economics and Management, Nanjing University of Aeronautics and Astronautics, Senior engineer. Research direction: Energy and environmental management; Tao Sun (1959-), Men, Born in Taian of Shandong province, Professor and doctoral supervisor of School of Economics and Management, Nanjing University of Aeronautics and Astronautics, Research direction: Environmental Finance; Tianyi Cao (1998-), Women, Born in Jiamusi of Heilongjiang province, master degree candidate, School of Economics and Management of Dalian University of Technology. Research direction: Environmental Finance.

\section{References}

1. Han Xiu-yan, SUN Tao, GAO Ming, 2018. Study on the New Urbanization Construction, Energy Consumption Growth and Carbon Emission Intensity Controlling. Soft Science. 32(9), 90-93.

2. Xiuyan Han, Tao Sun, Qing Feng (2019). Study on environmental pollution loss measurement model of energy consumption emits and its application in industrial parks. Science of the Total Environment, 668, 1259-1266.

3. Ridker, 1967. The determinants of residential property values with special reference to air pollution. The Review of Economics and Statistics, 49: 246-257.

4. M. Renshaw, R. P. Collins, A. Jenkins, R. Arndt, G. Carmichael, 1997. Predicting the effect of atmospheric pollution on soil and surface water acidification in the Middle Hills of Nepal. Science of The Total Environment, 208(1), 71-79.

5. Lipman Timothy E, Delucchi Mark A, 2002. Emissions of nitrous oxide and methane from conventional and alternative fuel motor vehicles. Clim Change, 53:477-516

6. Quah, Euston \&Boon,Tay Liam, 2003.The economic cost of particulate air pollution on health in Singapore. Journal of Asian Economics, Elsevier, 14(1), pages 73-90.

7. Elizabeth J. Wilson, Alexandra B. Klass, Sara Bergan, 2009. Assessing a Liability Regime for Carbon Capture 
and Storage. Energy Procedia, 1(1): 4575-4582.

8. García-Villanueva Luis Antonio and so on, 2014. Health Risk Assessment of Zone 7 Contaminated with Benzene in the Environmental Liability Generated by the "March 18th Ex-Refinery" in Mexico City. Ingeniería, Investigación y Tecnología, 15(3): 419-428

9. Sun Tao, Zhao Tian-yan, 2014. Research on Measurement Method of Corporate Environmental Responsibility of Pollutants and Its Application. China Population,Resources and Environment, 24(5),102-108.

10. Li Haidong, Shen Weishou, Jia Ming, Zhang Tao, 2015. Assessment of ecological damage and environmental pollution loss in large open pit mines. Journal of Nanjing Forestry University (Science edition),39 (6):112-118.

11. Rosalie van Zelm, Philipp Preiss, Thomas van Goethem, Rita Van Dingenen, Mark Huijbregts, 2016. Regionalized life cycle impact assessment of air pollution on the global scale: Damage to human health and vegetation. Atmospheric Environment, 134,129-137.

12. Niu Yue, Chen Renjie, Kan Haidong, 2017. Air Pollution, Disease Burden, and Health Economic Loss in China. Advances in experimental medicine and biology, 1017, 233-242.

13. Débora C. Marié, Marcos A. E. Chaparro, Juan M. Lavornia, Ana M. Sinito, Harald N. Böhnel, 2018. Atmospheric pollution assessed by in situ measurement of magnetic susceptibility on lichens. Ecological Indicators, 95(1), 831-840

14. A. Austruy, L. Yung, J. P. Ambrosi, O. Girardclos, M. Chalot.2019. Evaluation of historical atmospheric pollution in an industrial area by dendrochemical approaches. Chemosphere, 220,116-126,

15. Chen Shiyi, 2010. Shadow Price of Industrial Carbon Dioxide: Parametric and Nonparametric Approaches. The Journal of World Economy, (8),93-111.

16. Aigner D. and Chu S.F., 1968. On Estimating the Industry Production Function. American Economic Review, $58,226-239$.

17. Schmidt P.,1976. On the Statistical Estimation of Parametric Frontier Production Functions. Review of Economics and Statistics, 58(2), 238-239.

18. Tetsuya Tamaki, Kong Joo Shin, Hiroki Nakamura, Hidemichi Fuji, Shunsuke Managi, 2018. Shadow prices and production inefficiency of mineral resources. Economic Analysis and Policy, 57,111-121.

19. Pollak R. A., Sickles R C and Wales, T.J., 1984. The CES-Tran slog: Specification and Estimation of A New Cost function. Review of Economics and Statistics, 66(4), 602-607.

20. Gollop F.M. and Roberts M.J., 1985. Cost-minimizing Regulation of Sulfur Emissions: Regional Gains in Electric Power. Review of Economics and Statistics, 67, 81-90.

21. Pittman, R.W., 1981. Issues in Pollution Control: Interplant Cost Differences and Economies of Scale. Land Economics, 57, 1-17. 
22. Jeong-Dong Lee, Jong-Bok Park, Tai-Yoo Kim, 2002. Estimation of the shadow prices of pollutants with production environment inefficiency taken into account: a nonparametric directional distance function approach. Journal of Environmental Management, 64(4), 365-375,

23. María Molinos-Senante, Nick Hanley, Ramón Sala-Garrido, 2015. Measuring the $\mathrm{CO}_{2}$ shadow price for wastewater treatment: A directional distance function approach. Applied Energy, 144,241-249.

24. Hailu,A. and Veeman, T.S., 2000. Environmentally Sensitive Productivity Analysis of the Canadian Pulp and Paper Industry, 1959-1994: An Input Distance Function Approach. Journal of Environmental Economics and Management, 40, 251-274.

25. Lee, M., 2005. The Shadow Price of Substitutable Sulfur in the US Electric Power Plant: A Distance Function Approach. Journal of Environmental Management, 77(2), 104-110.

26. Rezek, J.P. and Campbell, R.C., 2007. Cost Estimates for Multiple Pollutants: A Maximum Entropy Approach. Energy Economics, 29(3), 503-519.

27. Guohua Feng, Apostolos Serletis, 2014. Undesirable outputs and a primal Divisia productivity index based on the directional output distance function, Journal of Econometrics, 183(1), 135-146.

28. Timo Kuosmanen, Andrew Johnson, 2017.Modeling joint production of multiple outputs in StoNED: Directional distance function approach. European Journal of Operational Research, 262(2), 792-801.

29. Guo Wen, Sun Tao, Zhu Jian-jun, Dai Hong-jun, 2017. Improvement of Network SBM Efficiency Evaluation Method in Associated Multi-stage Production System. Systems Engineering, 35(1), 151-158.

30. Fare R, Grosskopf S, Pasurka C A J, 2007. Environmental Production Functions and Environmental Directional Distance Functions. Energy, 32(7), 1055-1066. 
Figures

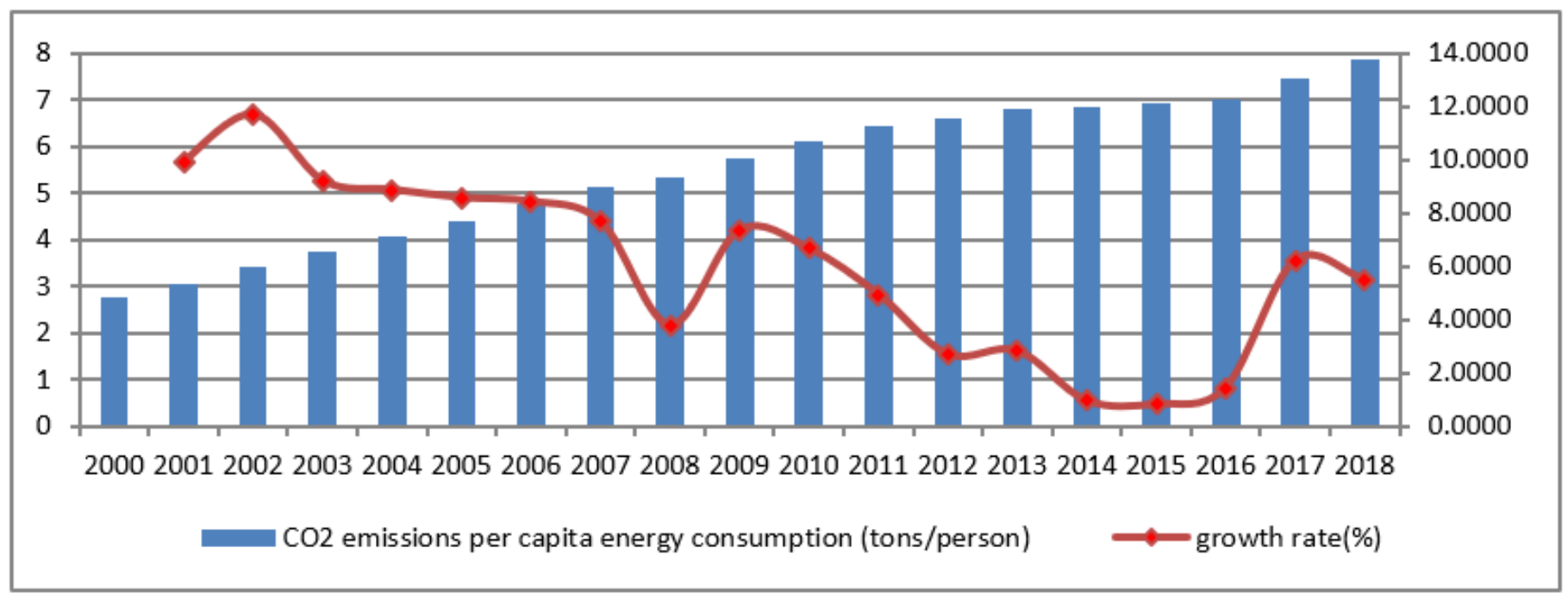

Figure 1

Industrial Energy Consumption CO2 Emission Intensity and Its Growth Trend Chart in China

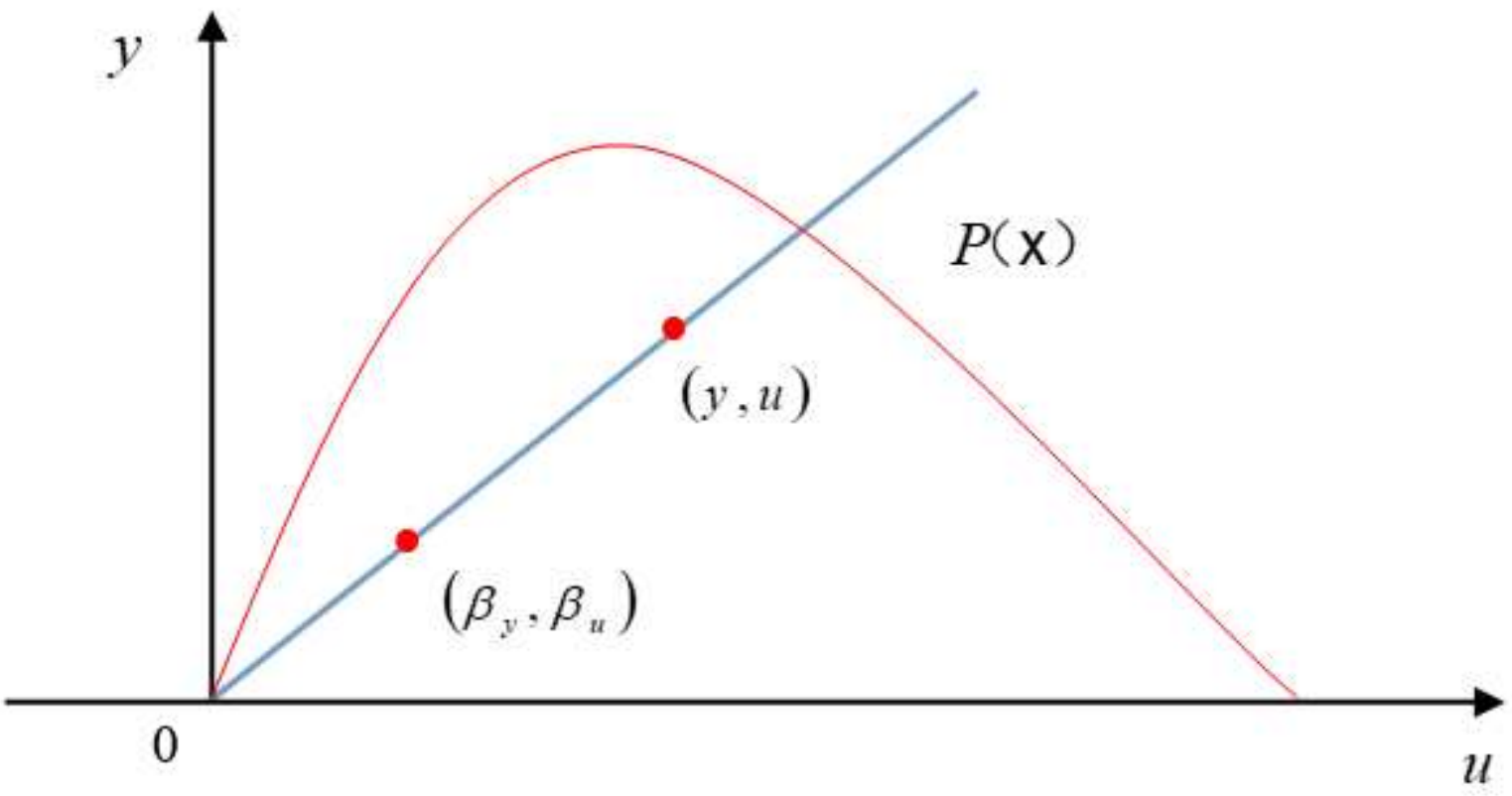

Figure 2

Principle diagram of environmental technology 


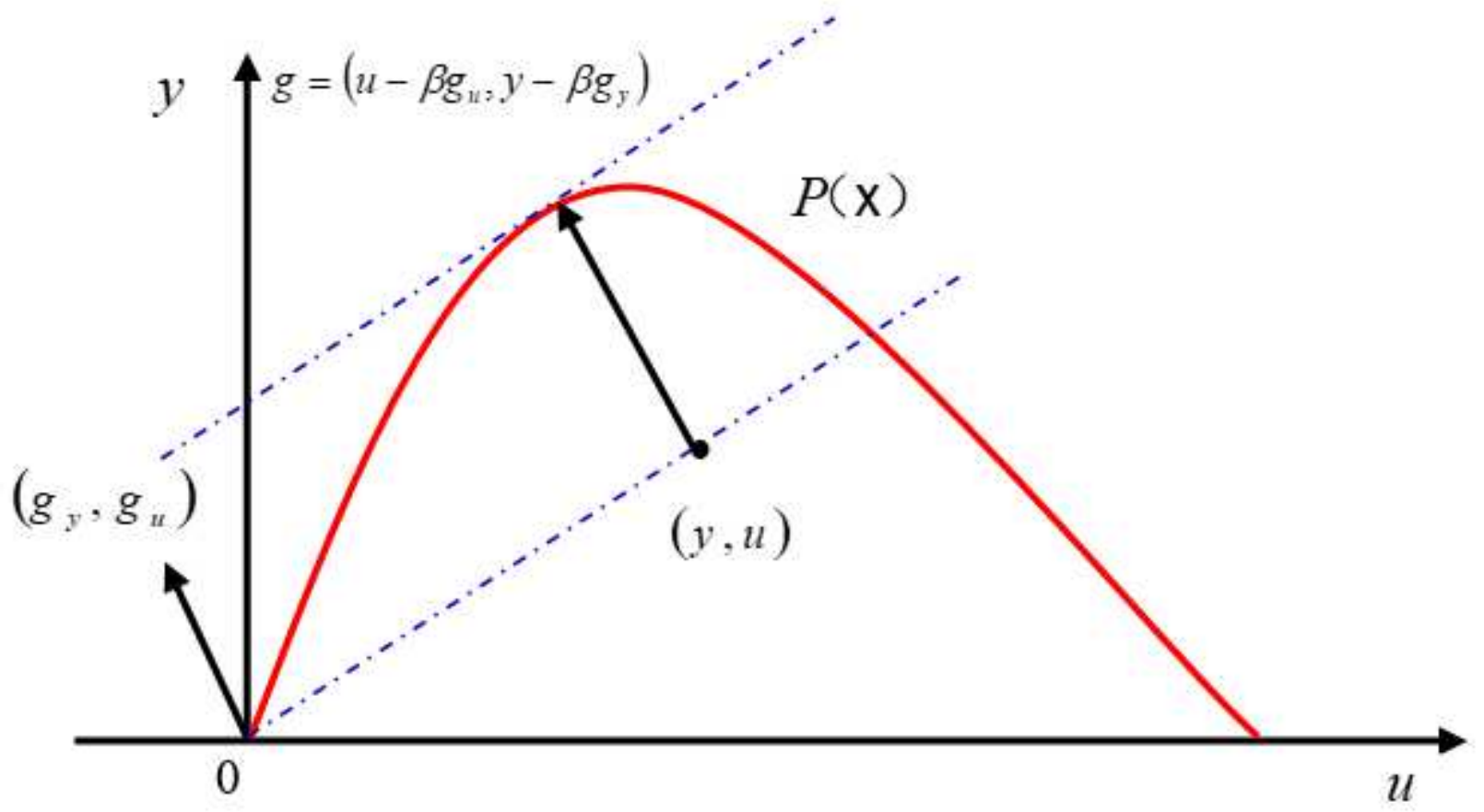

Figure 3

Schematic diagram of directional distance function distance function

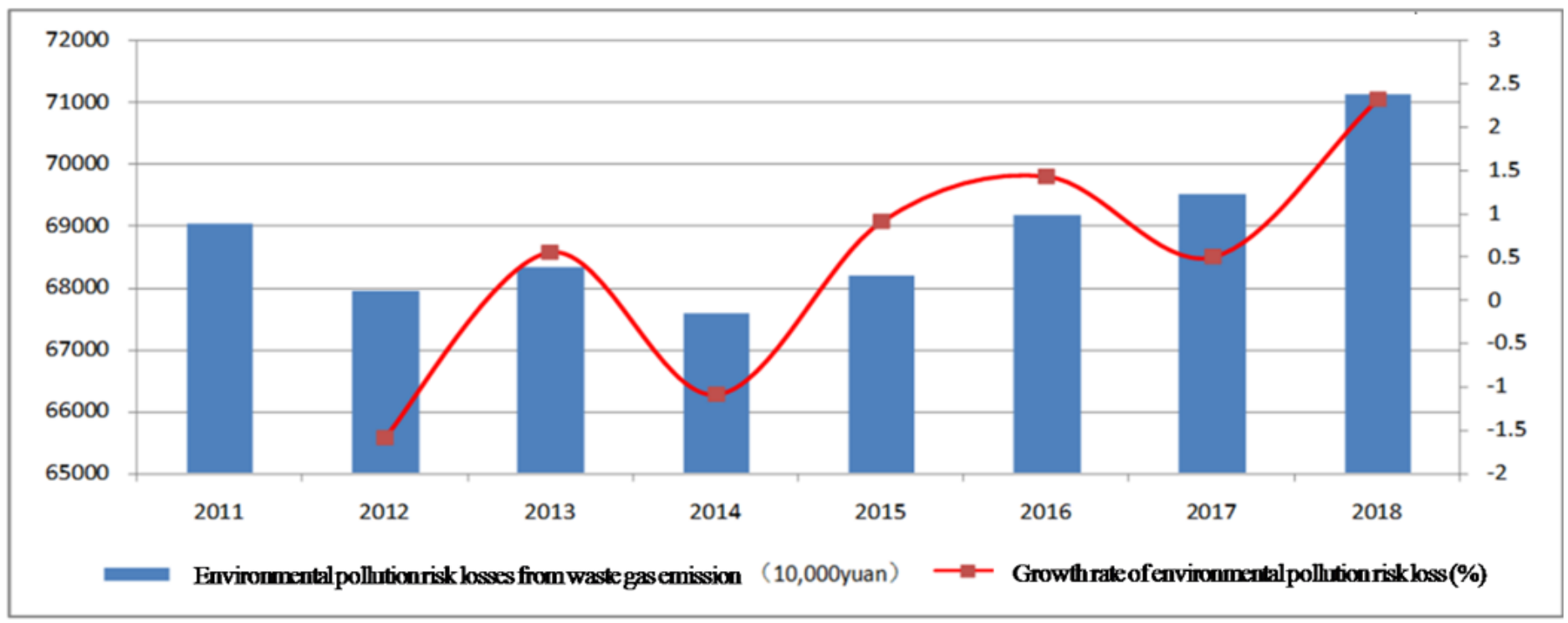

Figure 4

Environmental Pollution Loss and Growth Rate Trend Chart of waste gas emission in Nanjing MV Industrial Park 


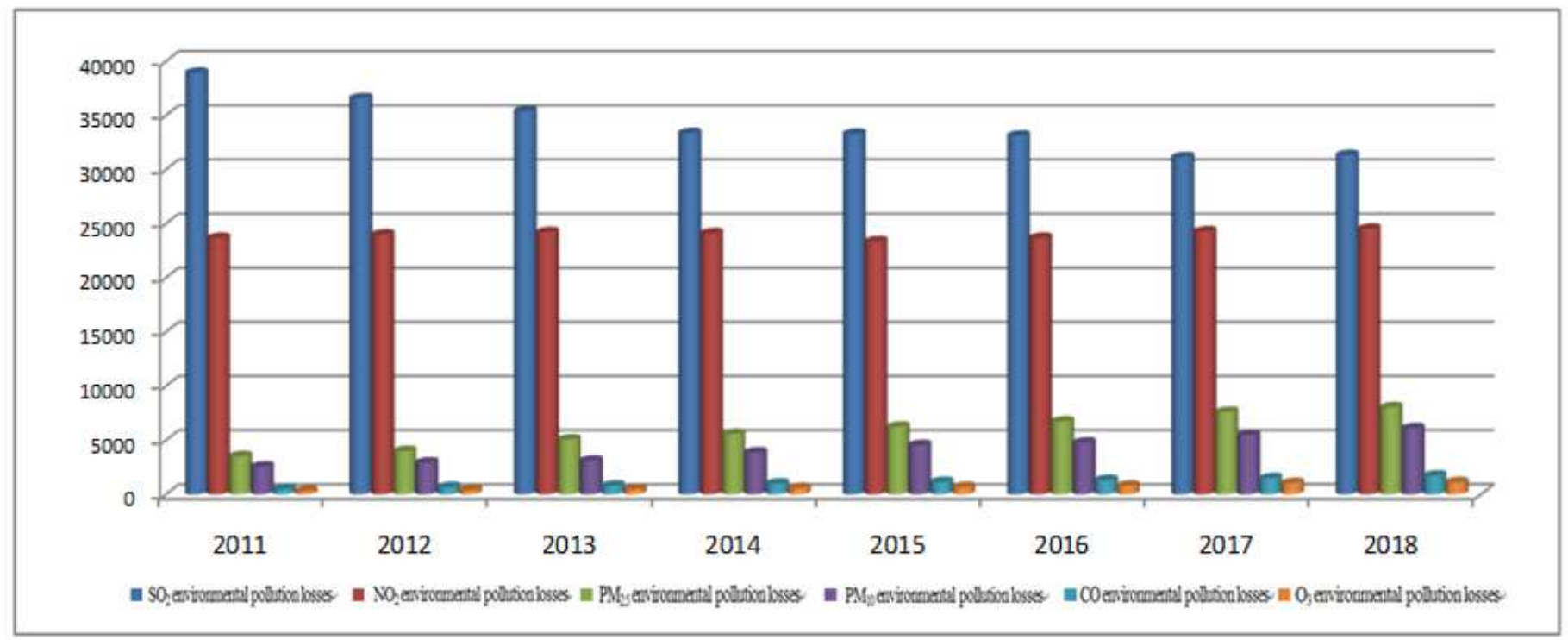

Figure 5

Environmental Pollution Loss Composition and Change Chart of Waste gas emission in MV Industrial Park of Nanjing

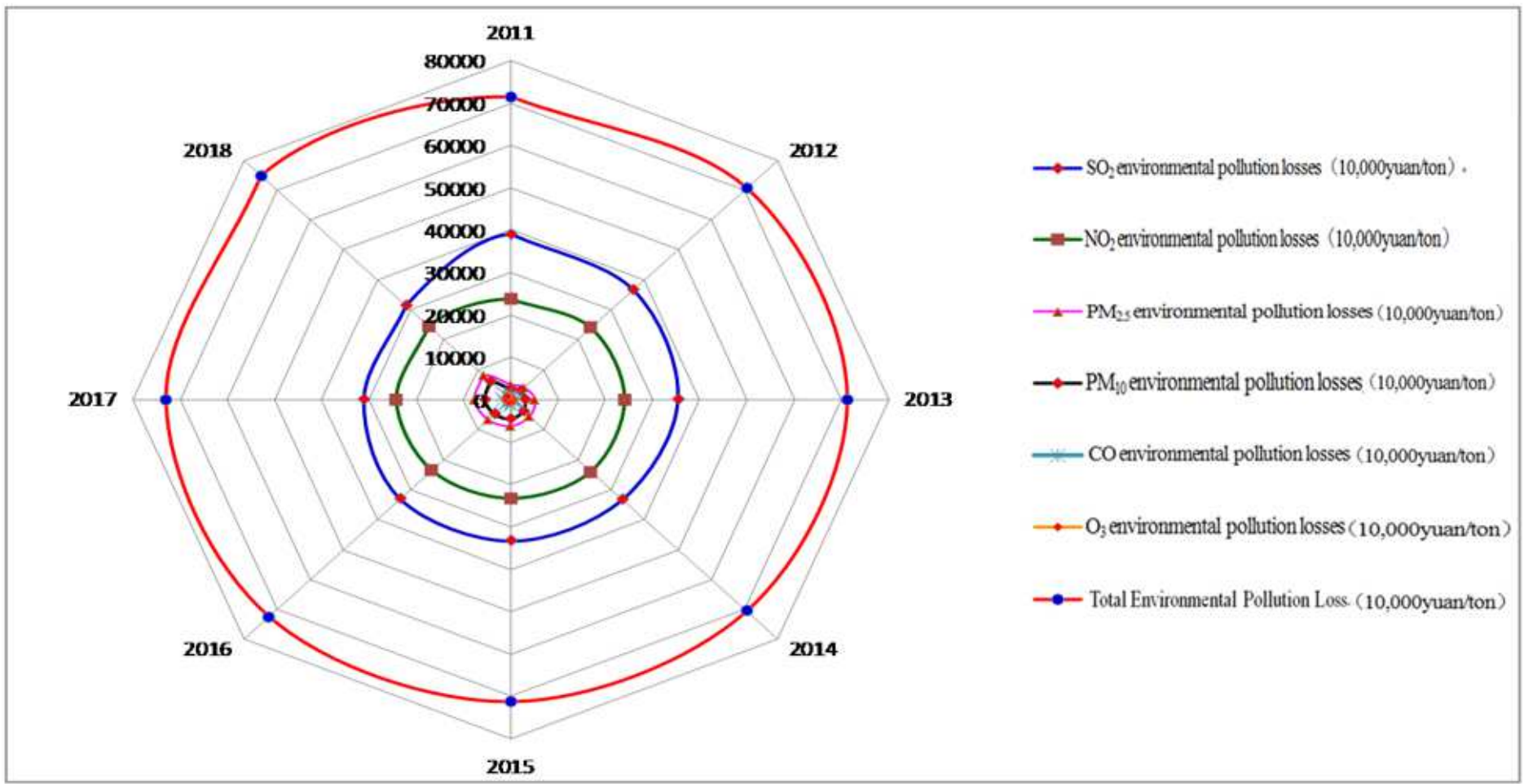

Figure 6

Radar Map of Environmental Pollution Loss Measurement Result of waste gas emission in Nanjing MV Industrial Park 


\section{Supplementary Files}

This is a list of supplementary files associated with this preprint. Click to download.

- GraphicalAbstract.pdf

- Highlights.pdf 